\section{A cidade como espaço de produção: um breve olhar sobre a obra de Tom Lisboa ${ }^{1}$}

\author{
Luciane Ruschel Nascimento Garcez
}

Professora de História da Arte, UNIVILLE, mestre em Teoria e História da Arte pela UDESC e doutoranda em Estudos e Ciências da Arte, Université de Provence.

Resumo

Como pensar uma cidade contemporânea, cada vez mais multicultural, tendo a arte como localizador? O que é o espaço contemporâneo local globalizado? Como definir a localidade em cidades cada vez mais multinacionalizadas? Este espaço é um atlas desenhado por entrelaçamentos, conexões fluxos e justaposições? A cidade é uma tessitura que liga lugares/ situaç̃es vizinhas, cospaço de culturas múltiplas que convivem entre si. E arte assim lis lugares/ situaçōes vizinhas, espaço de culturas múltiplas que convivem entre si. Earte assim as desvela. Interrogando saberes e problematizando o lugar como espaço que permeia a arte e se faz palco a ela, conclui-se que sim, o artista pode ajudar a problematizar o lugar contemporâneo, assim como o pesquisador que está refletindo sobre a questão interroga os saberes instituídos trazendo novos olhares a uma situaça que se modifica em velocidade vertiginosa: a cidade. Partindo destas questoes, pretende-se neste artigo analisar o trabalho Polaroides (In)visíveis de Tom Lisboa corm suas especificidades e intervenções.

Palavras-chave: Cidade; Arte; Tom Lisboa.

ABSTRACT

How to think a contemporary city, increasingly multicultural, with art as kind of compass? What is a contemporary globalized local space? How to set the local in increasingly multinational cities? This space is an atlas designed by entanglements, connections, flows and juxtapositions? The city is a fabric that connects places/situations surrounding space of multiple cultures that The city is a fabric that cond the interplay between art and it makes. What conclude that yes, the photographer place as 列 problematize the conterion, can inter changing at breakneck speed: the city. Based on these questions, this article aims to analyze the
work Polaroids (In) visible Tom Lisbon with their specificities and interventions. Keywords: City; Art; Tom Lisbon.

1 Este artigo é o desdobramento de uma pesquisa que foi apresentada na íntegra no $7^{\circ}$ Colóquio Franco-Brasileiro de Estética - Artes Visuais e o Lugar Contemporâneo, organizado pelo Programa de Pós-Graduação em Artes Visuais da Universidade Federal da Bahia em parceria com a Universidade de Sorbonne, Paris 8, sob direcão do Prof. Dr. François Soulages.

\section{[...] o espaço é um lugar praticado.}

Michel de Certeau

Como pensar uma cidade contemporânea, cada vez mais multicultural, tendo a arte como localizador? O que é o espaço contemporâneo local globalizado? Como definir a localidade em cidades cada vez mais multinacionalizadas? Este espaço é um atlas desenhado por entrelaçamentos, conexões, fluxos e justaposições? A cidade é uma tessitura que liga lugares/ situações vizinhas, espaço de culturas múltiplas que convivem entre si. E arte assim as desvela.

O objetivo deste texto é fazer uma breve e despretensiosa análise de alguns trabalhos do artista Tom Lisboa, abrindo uma oportunidade de discussão sobre a cidade como espaço de produção contemporânea a partir de algumas intervenções propostas pelo artista mencionado. O espaço urbano como material de produção poética não é algo novo no campo das artes, e Tom Lisboa o faz problematizando o olhar anestesiado do habitante comum, convidando a fazer parte de uma brincadeira que faz parte de sua pesquisa do espaço urbano como cenário e matéria prima para a arte.

Uma das características da sociedade contemporânea é a mobilidade, o trespasse de fronteiras, o desaparecimento destas fronteiras, mobilidade de pessoas, culturas, imagens, pensamentos e olhares, que vêm a dar corpo a um segmento da arte, a arte que problematiza o espaço, a cidade e suas subjetividades, as nuances que formam o sujeito em seu local de cotidiano. $O$ uso das novas tecnologias permite ultrapassar os limites da imagem, das oportunidades de dar a ver a imagem, os limites das fronteiras físicas. O mundo se coloca à disposição do espectador virtual, as imagens se deslocam, criando constelações, relações inusitadas, interrogando o inaudito.

Interrogando saberes e problematizando o lugar como espaço que permeia a arte e se faz palco a ela, conclui-se que sim, o artista pode ajudar a problematizar o lugar contemporâneo, assim como o pesquisador que está refletindo sobre a questão interroga os saberes instituídos trazendo novos olhares a uma situação que se modifica em velocidade vertiginosa: a cidade.

Efetivamente, se a forma estética da flânerie ressurge com força na experiência contemporânea, quer sob a forma de um sujeito em trânsito, liberto de constrangimentos geográficos e disponível para novos encontros potencializados pelas tecnologias digitais, quer através da navegação nômade na World Wide Web, nunca a errância, os trajetos e os comportamentos foram tão registrados, armazenados e controlados (CARVALHO, 2008, p. 2. Minha contagem. O texto original não possui numeração de página). Cartografados pelo indivíduo que os explora. Esta postura de flâneur remete ao poeta francês Charles Baudelaire, que criou esta figura no século XIX. Nas palavras deste artista,

Para o perfeito flâneur, para o observador apaixonado, é um imenso júbilo fixar residência no numeroso, no ondulante, no fugidio e no infinito. Estar fora de casa, e contudo sentir-se em casa onde quer que se encontre; ver o mundo, estar no centro do mundo e permanecer oculto no mundo, eis alguns dos pequenos prazeres desses espíritos independentes, apaixonados, imparciais, que a linguagem não pode definir senão toscamente. (BAUDELAIRE, 1988, p.170-171)

Mas para ser um flâneur é preciso estar disposto a desvendar a cidade e seus mistérios com cuidado, carinho, curiosidade, como se fosse um primeiro olhar. Certos artistas levam a 
esta forma de conhecimento do urbano, do local onde se vive, certos artistas incentivam que o sujeito também se entregue a este prazer, como num jogo de redescobrir o seu local. Segundo a teórica historiadora Sandra Makowiecky,

A forma pela qual a cidade é representada pelos seus artistas plásticos é usada como uma categoria analítica do fenômeno urbano nesta proposição, onde se percebe um miríade de conceitos que estabelece relações com sentimentos comuns às culturas joven urbanas: a memória como um movimento de resistência contra a apatia e a amnésia geradas por panorama de excessos, estabelecido pela cultura da mídia eletrônica e cibernética; as implicações das questões do corpo simulacro das descobertas da ciência, da solidão que destrói a vida urbana; a violência e a vida nas cidades em que figuram imagen solitárias e amedrontadas, procurando algum sentido numa teia de sentimentos de tédio e impotência, insegurança, deslocamento. Os artistas [.] se engajam em tentativas de Os artistas [...] se engajam em tentativas de algum tipo de postura diante do mundo da vid. (MAKOWIECKY; SIVA, 2009, p. 157)

Makowiecky discorre sobre o fenômeno das cidades invisíveis, onde o sujeito traça seu dia sem perceber seu entorno. Mudanças acontecem na cidade, pessoas circulam a paisagem se transforma, mas o sujeito indiferente ao seu entorno nada percebe. E é nesta ordem que certos artistas vão criar seus trabalhos, no intento de sensibilizar as pessoas para o local onde estão, onde circulam, onde vivem. Na produção contemporânea, continua sendo um tema que fascina, que apaixona, que impele a novos olhares, conceitos, reflexões. Pensar o seu lugar faz com que o artista perceba realmente o seu espaço, problematizar a cidade permite vê-la como antes não era possível, ou não era usual.

Certos artistas produzem sobre cidade falam sobre este espaço de vida e coexistência, problematizam suas peculiaridades e fragilidades; outros artistas produzem na cidade, ou seja, seus trabalhos são específicos em certos pontos físicos, não poderiam ser reproduzidos tal e qual foram pensados em outros espaços urbanos; mas existe uma gama de artistas que problematiza com a cidade, sendo assim, usam deste espaço para fazer o espectador refletir acerca do lugar onde vive, trabalha, seu trajeto cotidiano, etc.

O artista plástico goiano Tom Lisboa, radicado em Curitiba, Paraná, vem desenvolvendo um trabalho de pensar a cidade em vários locais do Brasil. Em maio de 2009 esteve em Florianópolis, onde desenvolveu um workshop com alunos da Universidade do Estado de Santa Catarina, UDESC, e fez uma palestra aberta ao público onde falou sobre o projeto Polaroides (in) visíveis, "As polaroides (in)visíveis e o descondicionamento do olhar", abordando justamente esta questão tão contemporânea das cidades em transformação e da falta de atenção, falta de apreensão desta pelas pessoas que por ali transitam. Estes trabalhos se tratam de intervenções no espaço urbano, onde as "polaroides" são fotografias feitas sem nenhum tipo de câmera, papel fotográfico e nem mesmo imagem. Ou seja, são papéis no tamanho das antigas fotografias tipo polaroide, onde o artista (ou qualquer outra pessoa que se disponha a participar do projeto) descreve o que está vendo de determinado ponto, e a chave da intervenção seria a questão do olhar e do deslocamento, que pode-se ler como uma referência à flânerie. Na ocasião da palestra e workshop com alunos da UDESC o ponto escolhido foi a Rua Felipe Schmidt, uma das ruas mais movimentadas do centro da cidade, onde cada participante recebeu uma polaroide ${ }^{1} \mathrm{e}$ a indicação de um 1 Polaroide no sentido do artista, ou seja, um telefone público (orelhão), para que a partir desse ponto estabelecesse sua descrição de imagem. A proposta era uma "receita", os participantes tinham de olhar a cidade a partir de um local pré-determinado pelo artista, e buscar ali o enquadramento de uma imagem ou espaço que motivasse o olhar.

A função da arte é construir imagens da cidade que sejam novas, que passem a fazer parte da própria paisagem urbana. Quando parecíamos condenados às imagens uniformemente aceleradas e sem espessura, típicas da mídia atual, reinventar a localização e a permanência. Quando a fragmentaçãa e o caos parecem avassaladores, defrontar-se com o desmedido avassaladores, defrontar-se com o desmedido das metropoles como uma nova experiência das escalas, da distancia e do tempo. Através dessas paisagens, redesc
(PEIXOTO, 2003, p. 15)

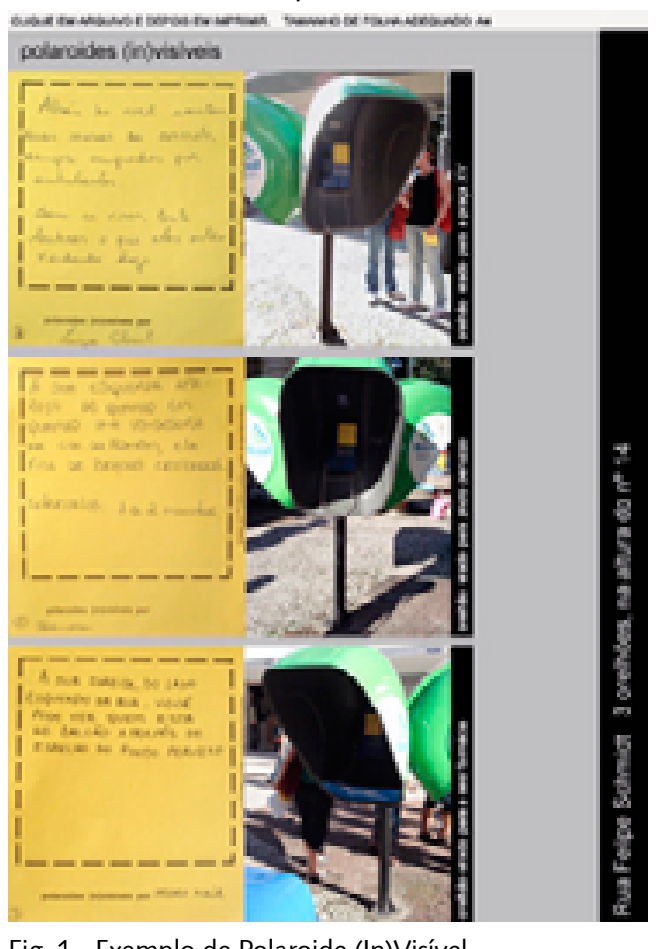

Fig. 1 - Exemplo de Polaroide (In)Visível Florianópolis, 2009.

Fonte: http://www.sintomnizado.com.br/polaroides

cartão amarelo, na mesma dimensão das antigas fotografias tipo polaroide, com espaço para que os alunos "escrevessem" sua fotografia, assim como Tom Lisboa faz em seus processos.
Foi esta a proposta de Lisboa, "redescobrir a cidade", como fala Peixoto. Este trabalho começou em 2005, em Curitiba, quando Tom Lisboa fez uma intervenção no centro da cidade instalando suas polaroides em telefones públicos, desconstruindo, de certo modo, o conceito de imagem fotográfica. Segundo o artista:

Sua execução surge a partir de um deslocamento que faço pela cidade, não deslocamento que ça pela cida de não é necessária a utilizaça de câmera para registrar que vejo a produção da imagem é transterida para quem le o texto da polaroide. Neste sentido, deslocamento parece ser uma palavra importante nesta intervenção: do artista, do olhar do espectador, do fazer fotográfico e da visibilidade muitas vezes estacionada que temos do local em que habitamos. Analogamente, as polaroides (in) visíveis discutem este deslocamento ao propor uma possível mobilidade entre o espaço real e o virtual. O espaço real é o da cidade, do espectador como criador de imagens, das obras que, efêmeras, são absorvidas pela agitação urbana. Já o espaço virtual é o da Internet, do registro do percurso que fiz dentro da cidade e da possibilidade de qualquer pessoa realizar a intervenção em meu lugar, ou seja, o espectador como interventor. (LISBOA, 2008a)

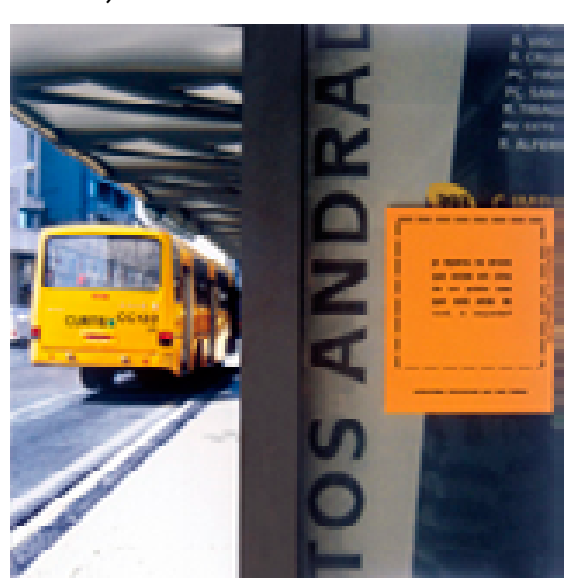

Fig. 2 - Ponto de ônibus da Praça Santos Andrade, centro de Curitiba, PR, em que foi instalada uma Polaroide (In)

Fonte: http://www.sintomnizado.com.br/polaroides 


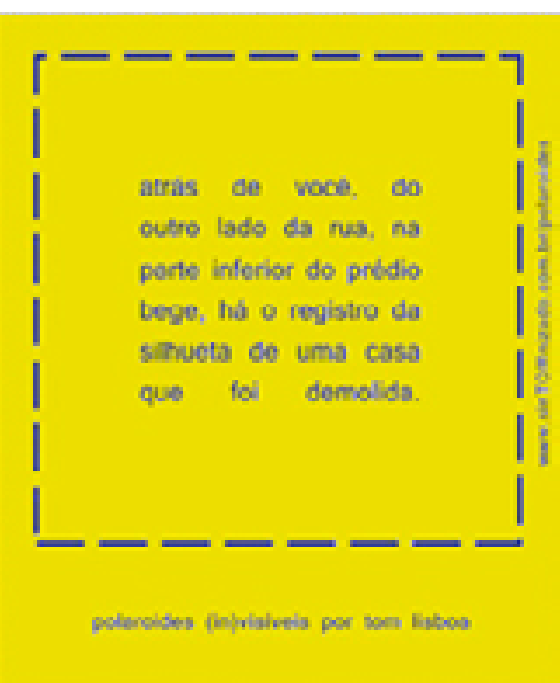

Fig. 3 - Exemplo de Polaroide (In)Visível, instalada na

praça Santos Andrade, Curitiba, 2005.
Dimensão $14 \times 11,5 \mathrm{~cm}$, impressão sobre papel sulfite amarelo.

Fonte: http://www.sintomnizado.com.br/polaroides

E assim o artista vem fazendo em várias cidades, problematizando a questão: o olhar cotidiano que não apreende o seu espaço de convivência, e como a cidade pode ser observada e experienciada pelo artista e pelo habitante mais desejoso de conhece seu entorno, e também oportuniza que as pessoas que participam de seu projeto realmente olhem sua cidade, comparem, troquem suas visões do espaço do entorno, uma vez que mais de um participante "descreve" sua polaroide partindo do mesmo ponto, e as diferenças nos textos de cada um são interessantes de se confrontarem, mostrando como o olhar de cada apreende diferenças, como o olhar de cada um absorve uma paisagem específica, muito particular. Cada qual vê o que lhe chama a atenção e, do mesmo ponto, cada "ponto de vista" é totalmente diferente do outro. Os resultados destas Polaroides (In)Visíveis, contendo já as descrições resultantes da observação do espaço, são colados com fita adesiva

em telefones públicos, locais de grande circulação e fácil acesso. Para o teórico Brissac Peixoto (2002), a intervenção, uma inscrição num fluxo mais amplo e complexo, que é a dinâmica urbana, implica em entender a cidade como algo em movimento, em várias direções. Assim, a leitura da cidade é feita de movimentos, intervalos, sequências, experiências e tempo.

Conforme Tânia Bloomfield, em um texto onde analisa estas ações de Tom Lisboa,

Uma das maiores qualidades dessa intervenção foi o de ter gerado instantes poéticos aos indivíduos que participaram poeticos aos Individuos que participaram dela, fazendo com que fossem muito além do mero pape de espectadores de um trabalho artístico, m meio à cidade. Ao contrário, participaram ativamente de sua realização. De outra forma, todos esses atores envolvidos na experiência artística, instigados pelo trabalho, podem contribuir para a reflexão e para a ação, necessárias às mudanças sociais e espaciais que a cidade requer. $(2009, s / p)$

Neste sentido cabe pensar que as obras revelam-se somente para quem decidir seguilas, e o olhar atento requer tempo, dedicação. Segundo a teórica Mônica Zielinsky (2003),

é um tipo de experiência que busca provocar espectador que em sua grande maiori não sabe que se trata de uma forma de arte, aproxima o individuo da obra e obra é a cidade, esse cenário denso do cotidiano urbano. Trazendo dessa forma novas percepções desse espaço rotineiro. Espaços percebidos. Reflexões, interrogações entre o limite entre arte e vida.

O trabalho de Tom Lisboa intensifica a percepção dos espaços que não são apreendidos pelo indivíduo e dessa forma o artista torna visível a paisagem urbana que usualmente passa despercebida ao habitante daquele lugar, "invisível", e que paradoxalmente costuma se "dar a ver" com outros olhos ao visitante, ao turista, àquele que não está habituado aos seus contornos e desvios, aquele que vê com novos olhos. Como bem cita Nelson Brissac Peixoto, a cidade contemporânea não é mais um pano de fundo das relações que nela se desenrolam, mas a própria vida cotidiana é constituída pelo urbano, pelo entorno (PEIXOTO, 2002).

Uma vez que as polaroides (in)visíveis são fixadas no local especificado com fita adesiva comum, elas tendem a desaparecer com muita rapidez. Por esta razão estas ações são amplamente documentadas e registradas, e qualquer pessoa interessada pode acessar estes registros no "Guia de Visitação On-line" do site de Tom Lisboa (SINTOMNIZADO, s.d.). O site permite também que qualquer um possa realizar sua intervenção urbana com as polaroides (in)visíveis onde e quando quiser. Basta acessar este "Guia", imprimir os cartões das polaroides e ir para o local indicado, seguindo os passos do artista.

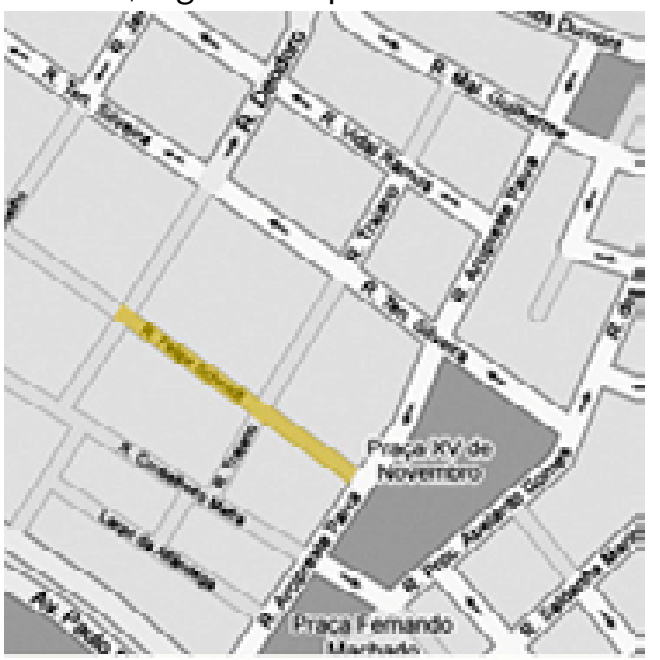

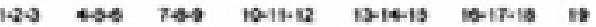
Fig. 4 - Exemplo de Polaroide (In)Visível, instalada na praça Santos Andrade, Curitiba 2005.

Dimensão $14 \times 11,5 \mathrm{~cm}$, impressão sobre papel sulfite amarelo.

Fonte: http://www.sintomnizado.com.br/polaroides

Após estas ações, Tom Lisboa expôs em alguns museus o registro destas intervenções, trazendo para dentro de espaços expositivos públicos e privados um pouco do espaço externo, o vernacular dentro do museu, imagens que são palavras, e que exigem do espectador a mesma atenção, o mesmo desvelo, pois o que o visitante pode apreciar nestas exposições, além das fotografias que mostram os locais onde as polaroides foram afixadas, são os cartões amarelos pendurados na parede, neste caso a exposição só é realmente apreendida, compreendida, se este parar, ler e dispensar o tempo necessário para que exista esta troca.

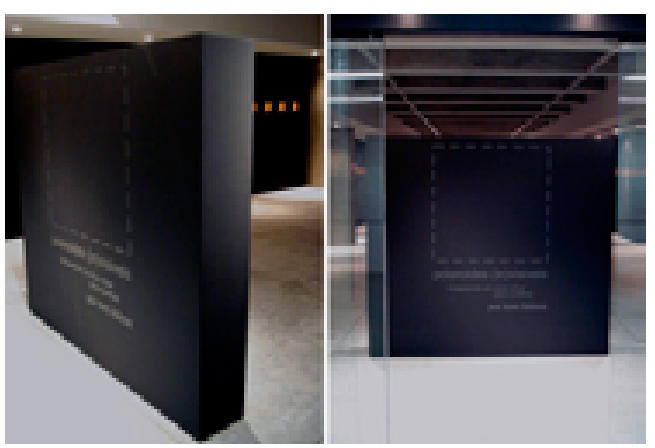

Fig. 5 - Entrada da exposição "Polaroides (in)visíveis", na Caixa Cultural, Galeria da Caixa, Curitiba, PR. 2007 Fonte: http://www.sintomnizado.com.br/polaroides

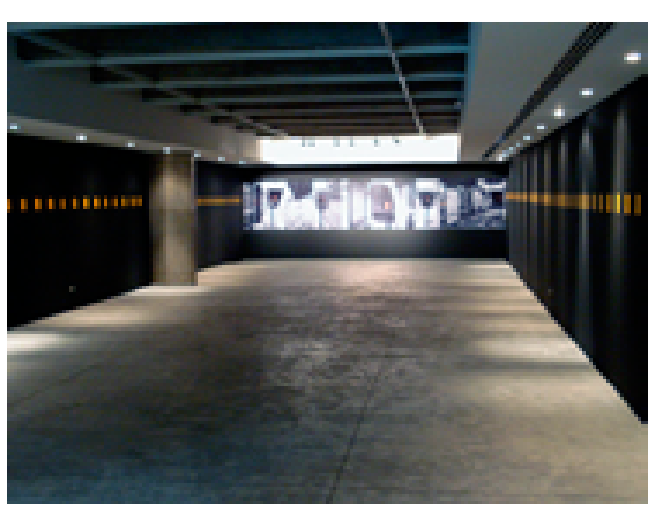

Fig. 6 - Interior da exposiçăo polaroides (in)visíveis, na Fonte: http://www sintomnizado com br/polaroides

Algumas curiosidades sobre as polaroides de Tom Lisboa: 
- Apesar de serem feitas sem câmera e não possuírem imagem, as polaroides (in) de Fotografia, a mais relevante premiação de Fotografia, a mais relevante premiação nacional nesta área.

- A primeira intervenção das polaroides (in) visíveis em Curitiba foi em 2005, nas praças Santos Andrade, Zacarias e Carlos Gomes. Foram confeccionadas 18 obras na época. - Em dois anos foram feitas, ao todo, 17 polaroides (in)visíveis: 118 para Curitiba, 36 para Porto Alegre, 16 para Vitória e 8 para Buenos Aires.

- Curitiba é a primeira cidade a ganhar um "guia de visitação" impresso. Antes só existiam os "guias de visitação on-line", na internet. - Para fazer 10 polaroides (in)visíveis Tom Lisboa gasta uma média de 3 horas observando a cidade.

- A Galeria da Caixa é o primeiro espaço ficial que Tom Lisboa expõe desde 2004 em Curitiba. Neste período, seus trabalho m curito form "marginais", independh feltos sem qualquer tipo de autorização ou eritos sem qualquer tipo de autorização ou

2006, Tom Lisboa ganhou "Voto de Louvor" da Câmara Municipal de Curitiba NIZADO, s.d.)

Em 2006,o artista criou um desdobramento desta ação, com proposta "Intervenções Privadas":

Uma "intervenção privada" consiste em inseri (sem autorizaça) as polaroides (in)visiveis (sem autorizça) as polarides (in)visíveis culturais tirar uma foto da exposiç̃ a montad culturais, tirar uma foto da exposição montad 28 museus, de 19 cidas, em 15 pa ano, 28 museus, de 19 cidades, em 15 paises, já (SINTOMNIZADO, s.d.)

Nesta ação o artista conta com o inesperado pelo fato de estar ali sem autorização, e retém somente o registro da ação, pois não tem um retorno das pessoas que possam perceber a ação, ou as polaroides. Estas intervenções aconteceram em diversos países, Argentina, Estados Unidos, Bélgica, França, Inglaterra, entre vários outros. Nas figuras abaixo, podem-se ver as imagens dos locais onde Tom Lisboa colou suas polaroides, e também como as descreveu, como são sua "imagens em palavras".

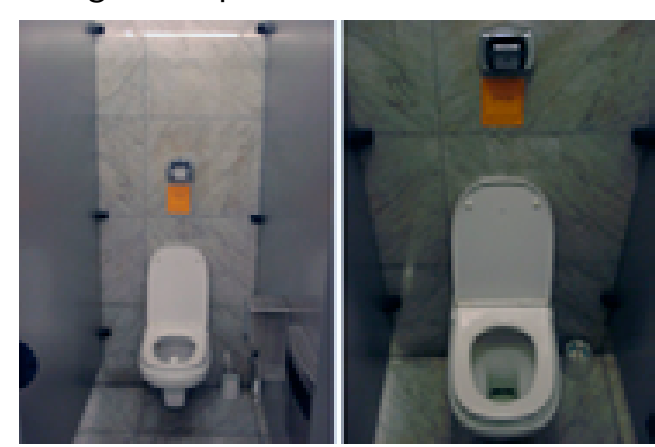

Fig. 7 - MALBA - MUSEU DE ARTE LATINO-AMERICANA DE BUENOS AIRES 19/10/2006 e 21/10/2006 (www.malba.org.ar) (inserção no banheiro e foto: Tom Lisboa, texto das polaroides (in)visiveis: Tom Lisboa)

onte: http://www.sintomnizado.com.br/polaroides

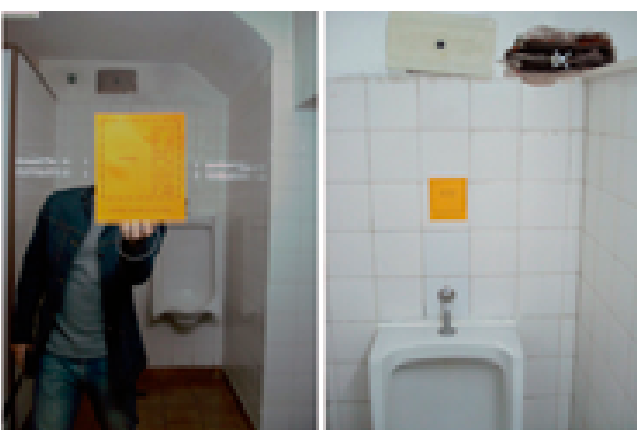

Fig. 8 - CENTRO CULtural RECOleta Buenos Aires, Argentina, inserção em agosto/2008 (centroculturalrecoleta.org/ccr-sp/) (nserção no banheiro e foto: Tom Lisboa, texto das
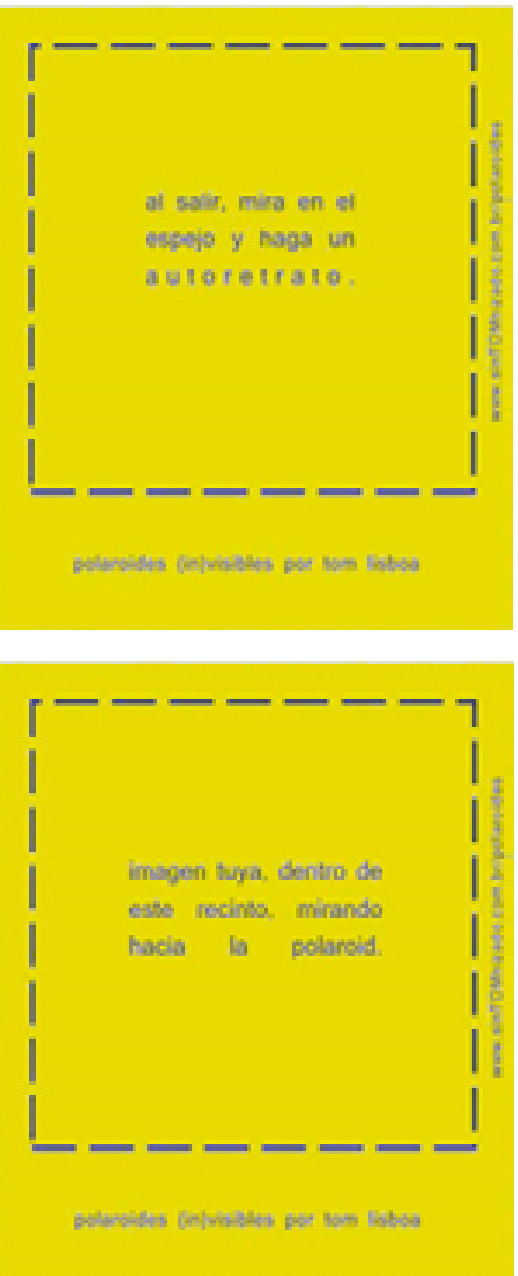

9 - Polaroides inseridas no MALBA e Museu Naciont de Belas Artes. Buenos Aires, Argentina. (inserção no banheiro e foto: Tom polaroides (in)visiveis: Tom Lisboa) Fonte: http://www.sintomnizado.com.br/polaroides

Sobre suas propostas, Tom Lisboa comenta a respeito de seu perambular, apreender:

Antes da intervenção Polaroides (in)visíveis, uma característica de minha pesquisa fotográfica era a imobilidad e não me refiro à imobilidade própria da fotografia mas a mou processo de da fotografia, mas ao meu processo de criaçăo. Eu năo costumava "sair para fotografar. Eram as den que vinham até mim, seja atraves da televisao ou das páginas dos jornais, que em papel fotográfico. (SINTOMNIZADO, s.d.)
Com esta ação, Tom Lisboa incentiva o olhar do espaço que não aparece no dia a dia, o espaço realmente "invisível" ao trajeto diário, dá luzes ao espaço vernacular, brinca com o complicado jogo de imagens da sociedade contemporânea.

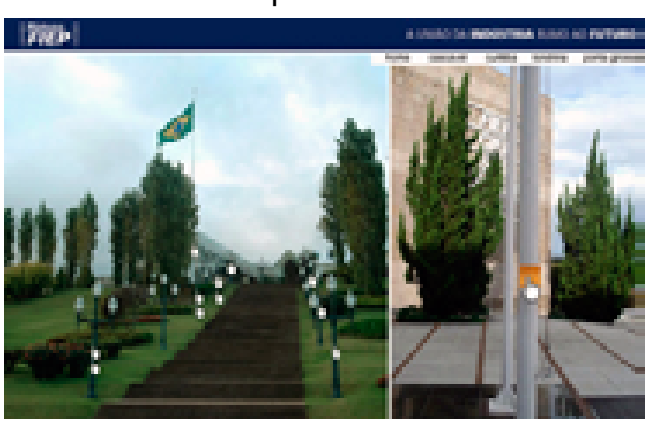

10 - Exemplo de Polaroide (In)visível, instalada na praça Santos Andrade, Curitiba, 2005.

Dimensão $14 \times 11,5 \mathrm{~cm}$, impressão sobre papel sulfite amarelo.

Fonte: http://www.sintomnizado.com.br/polaroides

É através da arte que se pode problematizar o contemporâneo, o espaço, o vernacular, a sociedade que transita neste atlas sem fronteiras, é na arte que se pode cartografar um mundo a cada dia, um mundo a cada obra.

\section{Referências Bibliográficas}

BAUDELAIRE, Charles. O pintor da vida moderna In: A modernidade de Baudelaire. Rio de Janeiro: Paz e Terra, 1988.

BLOOMFIELD, Tania. Paisagens e Lugares: uma abordagem da geografia cultural para intervenção urbana polaroides (in)visíveis, de Tom Lisboa, em Curitiba. In: ENCONTRO NACIONAL DE PESQUISADORES EM ARTES PLÁSTICAS, n. 17, 2008. Anais do $17^{\circ}$ Encontro Nacional de Pesquisadores em Artes Plásticas - ANPAP. 2008. Disponível em: http://www.anpap.org.br/anais/2008/ 
index.html.

CARVALHO, Margarida. Mapas Imaginários, out. 2008. Disponível em:

http://www.virose.pt/vector/b_21/carvalho. html\#_edn2.

LISBOA, Tom. Polaroides (In)Visíveis: fotos. Disponível em: http://www.sintomnizado. com.br/polaroides. Acesso em: 8 maio 2013 b.

Polaroides (In)Visíveis: sobre as Polaroides (In)Visíveis. Disponível em: http:// www.sintomnizado.com.br/polaroides_ sobreaspolaroides.htm. Acesso em: 8 maio $2013 a$.

MAKOWIECKY, Sandra; SILVA, Maria Cristina da Fonseca. Linhas Cruzadas: Artes Visuais em Debate. Florianópolis: Editora UDESC, 2009.

PEIXOTO, Nelson Brissac. Intervenções Urbanas: Arte/cidade. São Paulo: Ed. Senac São Paulo, 2002.

Paisagens Urbanas. São Paulo: Ed.

Senac São Paulo, 2003.

SINTOMNIZADO. Disponível em: http:// www.sintomnizado.com.br/polaroides_ cidades. Acesso em: 20 mar. 2013.

ZIELINSKY, Mônica. Os espaços reinventados na arte de Elaine Tedesco. In: TEDESCO, Elaine. Sobreposições imprecisas. São Paulo: Escrituras Editora, 2003. 